\title{
Software Requierement Specification Sistem Informasi Manajemen
}

\author{
Meme Susilowatia,", Alan Anggara Kusuma ${ }^{\mathrm{b}}$, \\ a, b Universitas Ma Chung, Villa Puncak Tidar Blok N No. 1, Malang, Jawa Timur 65151 \\ meme.susilowati@machung.ac.id
}

\begin{abstract}
Laporan ini berisi tentang hasil penelitian terkait software requirement specification informasi manajemen pada Usaha Dagang Wonorejo yang memiliki menu Sales and Marketing, Manufacturing and Production, Finance and Accounting. Pada pembuatan software requirement specification ini disusun berdasarkan ISO/IEC/IEEE 29148-2011, metode penelitiannya meliputi studi literatur dari buku atau tesis yang berkaitan dengan pembuatan dokumen software requirement, dokumen yang digunakan menjadi refrensi untuk studi literatur adalah tesis dari peneliti terdahulu, selain itu penulis juga menggunakan teori ISO/IEC/IEEE 29148-2011 sebagai dasar pembuatan dokumen software requirement specification sehingga dokumen tersebut akan memiliki standar internasional, lalu juga melakukan observasi lapangan dengan cara terjun secara langsung ke perusahaan untuk mempelajari alur bisnis yang diterapkan diperusahaan dan melakukan wawancara pada pihak yang terkait didalam perusahaan sehingga data yang didapat lebih akurat dan lebih obyektif. Dokumen software requirement specification ini juga dilengkapi dengan logical database dari menu sales and marketing, menu manufacturing and production, dan menu finance and accounting sehingga dengan pemaparan logical database yang terdapat didalam dokumen software requirement specification tersebut bisa digunakan untuk memudahkan penelitian yang selanjutnya guna melakukan analisis sehingga pengembang berikutnya akan lebih mudah untuk membuat dokumen software requirement specification yang lebih baik dari sebelumnya.
\end{abstract}

Kata Kunci-Logical database, Software requirement specification, ISO/IEC/IEEE 29148-2011, Sistem informasi manajemen perusahaan dagang.

\section{PENDAHULUAN}

Pada pengembangan software terdapat sebuah desain yang matang terlebih dahulu supaya software tersebut bisa menjangkau seluruh kebutuhan bisnis pada perusahaan, tidak seperti pada yahoo messenger vista yang bisa dibilang gagal dan kurang memenuhi kebutuhan perusahaan sehingga produk tersebut dihentikan, dan juga Google video player yang kurang mampu membuat konsumen terpancing untuk menggunakannya dikarenakan format video yang dapat diputar pada aplikasai tersebut sangat terbatas sedangkan diluar sana ada banyak sekali macam macam format pada video.

Dan pada artikel kali ini dimana perusahaan dagang wonorejo yang memilliki proses bisnis yang cukup luas namun belum memiliki sistem informasi manajemen yang memadai dalam menunjang kegiatan bisnis, dan pada jurnal Sistem Informasi Manajemen Penjualan Pada PT. Glory Sriwijaya Palembang oleh abdul gofur dan kawan kawan, sebuah perusahaan harus memiliki sistem informasi manajemen yang baik untuk menunjang kegiatan bisnisnya. Dan untuk merancang sistem informasi manajemen yang baik dibutuhkan sebuah SRS seperti pada jurnal Software Requirement Spesification Untuk Sistem Informasi Lulusan PT Swasta karya Teddy Marcus. Dengan ada nya SRS yang pada saat sebelum merancang sistem pada perusahaan akan membuat sistem tersebut lebih deliverable.

Dengan adanya SRS maka perancang sistem akan tau mengenai kebutuhan sistem yang dibutukan pada sistem informasi manajemen yang akan dirancang untuk perusahaan ini.

Analisis yang dilakukan oleh peneliti dalam membuat SRS ini yang pertama adalah melakukan studi literatur yaitu membaca peneliti terdahulu dan dokumen dokumen yang berkaitan dengan pembuatan SRS, lalu yang kedua adalah melakukan observasi yaitu terjun langsung ke lapangan untuk mempelajari proses bisnis yang ada pada perusahaan lalu barulah peneliti membuat dokumen SRS sistem informasi manajemen untuk perusahaan dagang wonorejo.

\section{METODE}

SRS yang akan dibuat akan berisi mengenai kebutuhan perangkat lunak secara spesifik pada 
perusahaan dagang wonorejo. Membuat rancangan sistem yang dapat menjangkau seluruh kegiatan bisnis yang ada pada perusahaan guna mempermudah dalam memperoleh informasi dalam kegiatan operasionalnya.

Sistem Informasi menejemen usaha dagang wonroejo terdiri dari 3 menu, setiap menu yang ada berisikan konten yang bervariasi sesuai dengan kebutuhan tiap divisi pada perusahaan.

\section{ANALISIS}

Pada perusahaan ini memiliki proses bisnis yang cukup luas dan sistem yang berjalan saat ini tidak mampu untuk menjangkau seluruh proses bisnis yang ada.

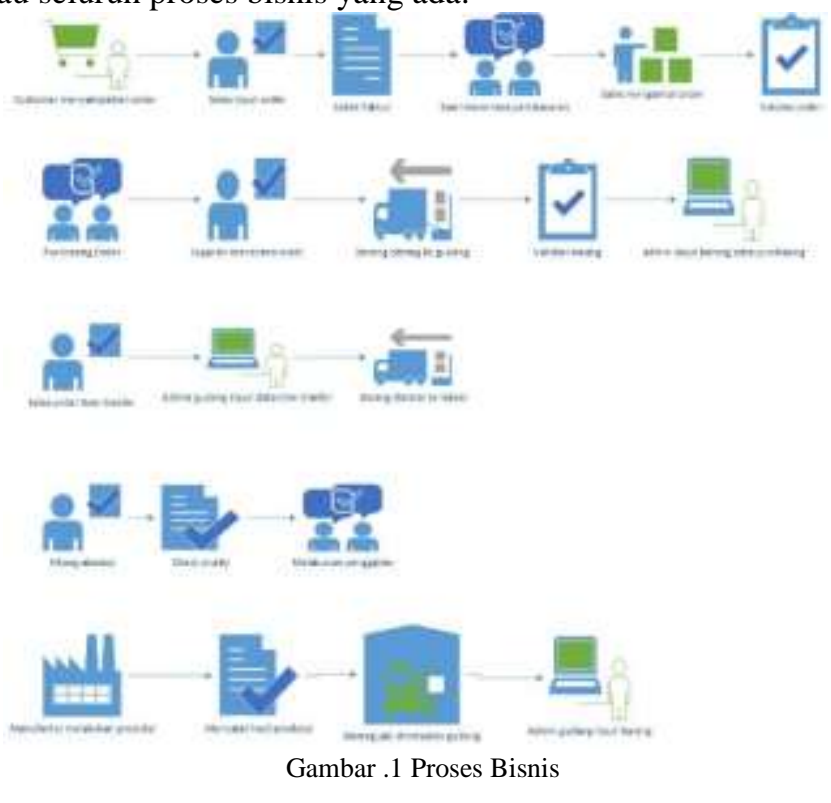

Pada bagian manufaktur masih manual dalam melakukan pencatatan persiapan produksi dan ketika barang produksi sudah jadi juga masih manual, kegiatan manual ini sangat rawan sekali terjadi error.

Pada proses penggajian karyawan juga masih manual, dimulai dari menghitung absensi karyawan dan darisitu akan ditentukan besar gaji bulanan dan bonus mingguan yang akan diterima untuk karyawan.

Pada saat menambahkan Sub Menu Production Planning minimal diperlukan untuk input masuknya barang mentah dan output barang jadi. Untuk tambahan keterangan dapat ditambahkan waktu pembuatan, target produksi harian, dan juga kapasitas peralatan.

Pada Sistem Informasi Usaha Dagang Wonorejo saat ini juga masih belum berdampak pada beberapa proses bisnis yang ada, antara lain seperti pada bagian cash management yang berisi tentang penggajian karyawan dimana saat ini masih dilakukan dengan cara manual tanpa komputer, lalu di bagian manufaktur juga belum terdapat sistem procurement sehingga dalam mencari supplier yang tepat masih harus melihat data satu per satu dan belum otomatis langsung menemukan, setelah itu juga pada sub menu production planning masih belum tersistem dalam computer dan pencatatan report nya masih bersifat manual yaitu dengan cara dicatat menggunakan kertas, lalu juga belum ada sistem quality control sehingga terkadang barang hasil produksi kurang memenuhi standar untuk dijual masih dimasukan kedalam kategori layak jual, dan belum adanya modul shipping dan untuk saat ini pengiriman barang masih manual sehingga perusahaan tidak mengetahui dengan jelas kendaraan mana yang berangkat dan siapa pengemudi kendaraannya, dan belum sistem transportation execution karena biaya yang dikeluarkan perusahaan dalam mengirim barang dianggap rendah, dan yang terakhir yaitu belum ada nya sub menu fixed asset dimana sub menu ini akan membantu bagian akuntan dan keuangan dalam memberikan informasi mengenai aset aset yang dimiliki perusahaan. 


\section{HASIL}

A. Mind map SIM usaha dagang wonorejo

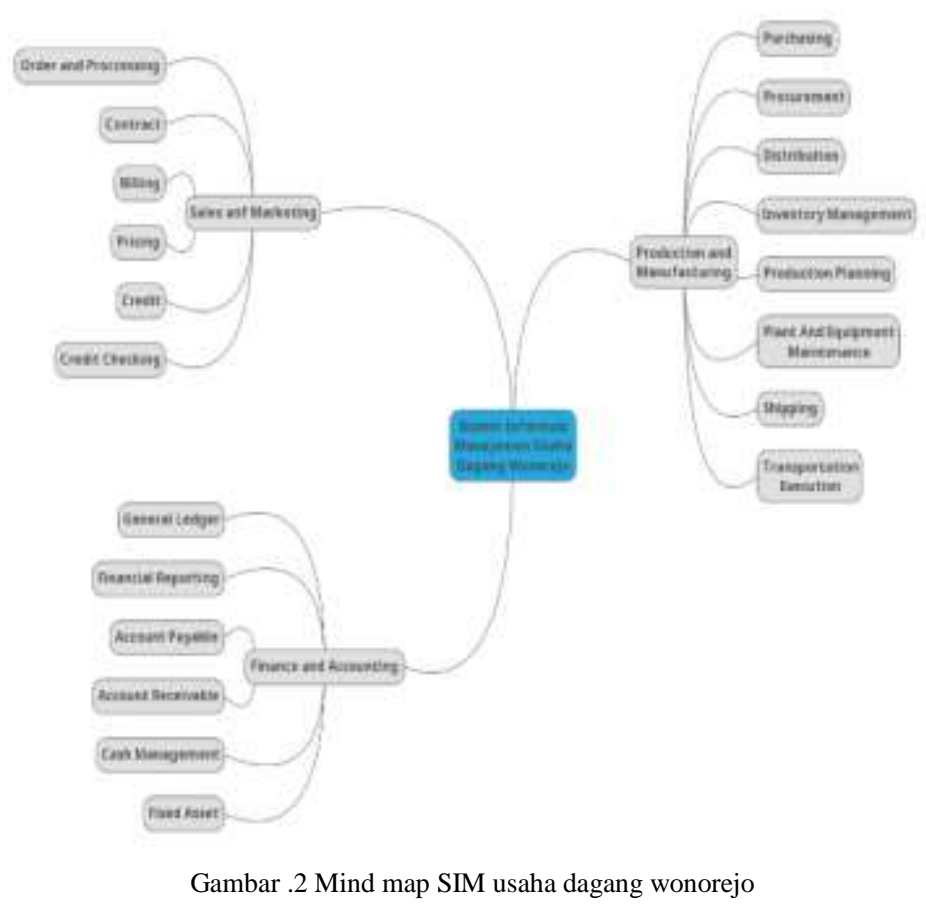

- Menu Sales and Marketing

Pada теnи ini Sistem dapat melakukan kegiatan penjualan dan akan digunakan oleh divisi Sales and marketing, berisi beberapa sub тепи.

- Order and Processing

Pada sub тепи ini tujuannya adalah untuk memudahkan proses order yang dilakukan oleh sales untuk memenuhi permintaan customer.

- Contract

pada sub теnи ini akan dapat membuat dan menampilkan kontrak kontrak yang sudah dilakukan oleh perusahaan dengan perusahaan lain.

- Pricing

Di sub menu ini bertujuan ketika melakukan transaksi user tidak perlu repot repot menginput harga barang kembali pada saat terjadi transaksi.

- Billing

dengan sиb тепи ini akan memudahkan kasir dalam melakukan arship faktur baik secara fisik maupun data.

- Credit

Tujuan dengan adanya sub menu credit yaitu untuk memudahkan user dalam melakukan pembatasan kredit dan juga menetapkan jatuh tempo pembayaran transaksi pada customer.

- Credit checking

Dalam sub menu credit checking akan memudahkan user dalam memantau limit credit dan Jatuh tempo pada pelanggan yang melakukan kredit.

- Menu Manufacturing and Production

Pada menu ini sistem akan memudahkan staff di bagian manufaktur dan produksi dimana menu ini berisikan tentang pembelian, Gudang, manufaktur, dan produksi. Dalam mеnи ini juga terdapat beberapa sub тепи.

- Purchasing

Pada sub тепи ini tujuannya untuk melancarkan sirkulasi gudang agar Gudang selalu terisi barang dengan jumlah yang efisien dan tidak terjadi kekosongan barang. 
- Procurement

Pada sub-menu ini bertujuan untuk memudahkan user dalam mencari supplier yang tepat untuk memenuhi kebutuhan perusahaan.

- Distribution

Dalam sub menu ini sistem akan menjadi jembatan distribusi barang antara Gudang dan toko sehingga toko dapat melakukan transaksi dengan lancar.

- Inventory management

dalam sub mеnu ini bertujuan untuk tata kelola Gudang sebagai tempat penampung barang baik dari purchasing ataupun manufaktur sehingga barang pada Gudang dapat dikelola dengan mudah.

- Production planning

Dalam sub menu ini tujuannya adalah agar barang yang telah diproduksi bisa langsung terjual dan untuk meminimalisir akan terjadinya dead stock.

- Quality Control

Pada sub menu ini bertujuan untuk membantu dalam pemeriksaan barang yang tidak layak dipasarkan yang diperoleh dari purchasing maupun manufaktur.

- Plant and equipment maintenance

Pada sub mеnu ini bertujuan untuk memudahkan dalam mengetahui biaya yang dibutuhkan untuk melakukan maintenance peralatan produksi yang digunakan oleh perusahaan.

- Menu Finance and Accounting

Pada menu ini sistem akan menampilkan laporan keuangan dan juga accounting yang diambil berdasarkan transaksi pada penjualan dan pembelian sehingga dapat dilihat report nya. Dan pada menu ini juga ada beberapa sub menu mengenai keuangan dan akuntansi.

- Financial reporting

Pada bagian ini bertujuan untuk memudahkan divsi finance and accounting dalam melakukan pembukuan dan melihat laporan keuangan sehingga tidak terlalu memakan banyak waktu ketika melakukan kegiatan operasional.

- Account payable

Pada bagian account payable bertujuan untuk memantau pembelian yang bersifat kredit sehingga user dapat mengetahui account payable yang dimiliki perusahaan.

- Account receivable

Pada sub menu account receivable bertujuan untuk memantau penjualan yang berdifat kredit sehingga user dapat mengetahui piutang yang dimiliki perusahaan.

- General ledger

Tujuan dengan adanya sub menu general ledger supaya user dapat melihat buku besar sebagai laporan keuangan perusahaan secara general.

- Cash management

Pada sub menu ini bertujuan untuk memudahkan user dalam memantau pengeluaran keuangan yang dilakukan untuk melakukan penggajian.

- Fixed asset

Pada sub menu ini bertujuan untuk memudahkan dalam melakukan kalkulasi total asset yang dimiliki oleh perusahaan berupa aktifa tetap dan aktifa lancar.

\section{B. Table Master}

- Menu Sales and Marketing

Pada Bagian ini akan dipaparkan semua table master sub menu yang ada didalam Menu Sales and Marketing. Menu dibuat untuk memudahkan transaksi penjualan pada divisi Sales and marketing.

- Submenu Order and Processing

sub тепи ini tujuannya adalah untuk memudahkan proses order yang dilakukan oleh sales untuk memenuhi permintaan customer. Terdiri dari 5 master yaitu Master Pelanggan, Master Karyawan, Master Barang, Master Jabatan, Master Divisi. 


\section{- Submenu Contract}

pada sub тепи ini akan dapat membuat dan menampilkan kontrak kontrak yang sudah dilakukan oleh perusahaan dengan perusahaan lain. Terdiri dari 5 master yaitu Master Pelanggan, Master Karyawan, Master Barang, Master Jabatan, Master Divisi

- Submenu Pricing

Di sub тепи ini bertujuan ketika melakukan transaksi user tidak perlu repot repot menginput harga barang kembali pada saat terjadi transaksi. Terdiri dari 5 master yaitu Master Pelanggan, Master Karyawan, Master Barang, Master Jabatan, Master Divisi

- Submenu Billing

dengan sub menu ini akan memudahkan kasir dalam melakukan arship faktur baik secara fisik maupun data. Terdiri dari 5 master yaitu Master Pelanggan, Master Karyawan, Master Barang, Master Jabatan, Master Divisi

- Submenu Credit

Tujuan dengan adanya sub menu credit yaitu untuk memudahkan user dalam melakukan pembatasan kredit dan juga menetapkan jatuh tempo pembayaran transaksi pada customer. Terdiri dari 5 master yaitu Master Pelanggan, Master Karyawan, Master Barang, Master Jabatan, Master Divisi

- Submenu Credit Checking

Dalam sub тепи credit checking akan memudahkan user dalam memantau limit credit dan Jatuh tempo pada pelanggan yang melakukan kredit. Terdiri dari 5 master yaitu Master Pelanggan, Master Karyawan, Master Barang, Master Jabatan, Master Divisi.

- Menu finance and accounting

Pada Bagian ini akan dipaparkan semua table master sub menu yang ada didalam Finance and Accounting. Bagian ini sangat berguna bagi user dalam melihat laporan keuangan dan akuntansi di perusahaan

- Submenu Financial Reporting

Sub menu ini bertujuan untuk memudahkan divsi finance and accounting dalam melakukan pembukuan dan melihat laporan keuangan sehingga tidak terlalu memakan banyak waktu ketika melakukan kegiatan operasional. Terdiri dari 8 master yaitu Master Pelanggan, Master Karyawan, Master Barang, Master Jabatan, Master Divisi, Master Supplier, Master Lokasi, Master Armada

- Submenu Account Payable

Pada bagian account payable bertujuan untuk memantau pembelian yang bersifat kredit sehingga user dapat mengetahui account payable yang dimiliki perusahaan. Terdiri dari 6 Master yaitu Master Pelanggan, Master Karyawan, Master Jabatan, Master Divisi, Master Barang, Master Supplier, Master Lokasi.

- Submenu Account Receiveable

Pada sub menu account receivable bertujuan untuk memantau penjualan yang berdifat kredit sehingga user dapat mengetahui piutang yang dimiliki perusahaan. Terdiri dari 5 Master yaitu Master Karyawan, Master Jabatan, Master Divisi, Master Barang, Master Pelanggan.

- Submenu General Ledger

Tujuan dengan adanya sub menu general ledger supaya user dapat melihat buku besar sebagai laporan keuangan perusahaan secara general. Terdiri dari 9 Master yaitu Master Pelanggan Master Karyawan, Master Barang, Master Jabatan, Master Divisi, Master Supplier Master lokasi, Master Armada, Master asset.

- Submenu Cash Management

Pada sub тепи ini bertujuan untuk memudahkan user dalam memantau pengeluaran keuangan yang dilakukan untuk melakukan penggajian. Terdiri dari 3 Master yaitu Master Karyawan, Master Divisi, Master Jabatan.

- Submenu Fixed asset

Pada sub menu ini bertujuan untuk memudahkan dalam melakukan kalkulasi total asset yang dimiliki oleh perusahaan berupa aktifa tetap dan aktifa lancar. Terdri dari 4 Master yaitu, Master Karyawan, Master Jabatan, Master Divisi, Master Asset. 
- Manufacturing and Production

Pada tabel master menu ini akan dipaparkan database yang berkaitan dalam bagian manufaktur dan produksi. Pada bagian ini terdapat sub menu yang bertujuan untuk memudahkan para karyawan untuk melakukan reporting dalam kegiatan operasionalnya.

- Submenu Purchasing

Pada sub menu ini tujuannya untuk melancarkan sirkulasi gudang agar Gudang selalu terisi barang dengan jumlah yang efisien dan tidak terjadi kekosongan barang. Terdiri dari 6 master yaitu Master Barang, Master Lokasi, Master Supplier, Master Karyawan, Master Jabatan, Master Divisi.

- Submenu Procurement

Pada sub-menu ini bertujuan untuk memudahkan user dalam mencari supplier yang tepat untuk memenuhi kebutuhan perusahaan. Terdiri dari 6 master yaitu Master Barang, Master Lokasi, Master Supplier, Master Karyawan, Master Jabatan, Master Divisi.

- Submenu Distribution

Dalam sub mепи ini sistem akan menjadi jembatan distribusi barang antara gudang dan toko sehingga toko dapat melakukan transaksi dengan lancar. Terdiri dari 5 Master yaitu Master Karyawan, Master Jabatan, Master Divisi, Master Barang, Master Lokasi

- Submenu Inventory Management

dalam sub menu ini bertujuan untuk tata kelola Gudang sebagai tempat penampung barang baik dari purchasing ataupun manufaktur sehingga barang pada Gudang dapat dikelola dengan mudah. Terduru dari 5 Master yaitu Master Karyawan, Master Jabatan, Master Divisi, Master Barang, Master Lokasi.

- Submenu Production Planning

Dalam sub тепи ini tujuannya adalah agar barang yang telah diproduksi bisa langsung terjual dan untuk meminimalisir akan terjadinya dead stock. Terdiri dari 5 Master yaitu Master Karyawan, Master Jabatan, Master Divisi, Master Barang, Master Lokasi.

- Submenu Quality Control

Pada sub menu ini bertujuan untuk membantu dalam pemeriksaan barang yang tidak layak dipasarkan yang diperoleh dari purchasing maupun manufaktur. Terdiri dari 4 Master yaitu Master Karyawan, Master Jabatan, Master Divisi, Master Barang,

- Submenu Master Plant and Equipment Maintenance

Pada sub menu ini bertujuan untuk memudahkan dalam mengetahui biaya yang dibutuhkan untuk melakukan maintenance peralatan produksi yang digunakan oleh perusahaan. Terdiri dari 4 Master yaitu Master Karyawan, Master Jabatan, Master Divisi, Master Peralatan.

- Submenu Shipping

Dalam sub mеnu ini bertujuan untuk memudahkan user dalam memantau semua transaksi yang bersifat delivery dan memudahkan bagian finance and accounting dalam menghitung biaya yang dikeluarkan untuk melakukan maintenance armada. Terdiri dari 6 Master yaitu Master Karyawan, Master Jabatan, Master Divisi, Master Armada, Master Barang, Master Pelanggan

\section{KESIMPULAN}

Berdasarkan pelaksanaan penelitian tugas akhir ini dapat ditarik kesimpulan yang dapat diuraikan sebagai berikut:

1. Dokumen SRS yang telah dibuat sudah memenuhi standar internasional ISO/IEC/IEEE 29148 2011 untuk dokumen software requirement specification.

2. Dengan adanya dokumen ini diharapkan pengembangan sistem akan bisa menjawab kebutuhan proses bisnis yang ada pada Usaha Dagang Wonorejo yang lebih terarah, lebih terfokus, dan lebih mudah bagi developer karena memiliki dokumen acuan dan panduan dalam pengembangan sistem. 


\section{REFERENCES}

[1] ISO/IEC/IEEE 29148. Systems and Software Engineering - Life Cycle Processes - Requirements Engineering. Basignstoke: Palgrave Macmillan, 2011.

[2] Dimas Pradhana Putra. Spesifikasi Dan Desain Kebutuhan Perangkat Lunak Pada Website Universitas Ma Chung Malang. Universitas Ma Chung: Malang, 2018

[3] Meme Susilowati S.kom., MMSI. Desain Proses Bisnis Sistem Informasi Ecommerce B2C Untuk Startup Micro, Kecil dan Menengah Sebagai Penyokong Digital. Universitas Ma Chung: Malang, 2017.

[4] James A. O'Brien, George M. Marakas Management Information Systems. Salemba empat: Surabaya, 2013

[5] Teddy Marcus Z. Software Requirement Spesification Untuk Sistem Informasi Lulusan PT Swasta. 2000

[6] Abdul Gofuur Lubis, Firmansyah, Desy Iba Ricoida, Iis Pradesan, Sistem Informasi Manajemen Penjualan Pada PT. Glory Sriwijaya Palembang. STIMIK GI MDP: Palembang,

[7] Abdul Kadir, Pengenalan Sistem Informasi Edisi Revisi. ANDI: Yogyakarta, 2014. 